\title{
A field approach to eradication of porcine epidemic diarrhoea virus in a breeding pig farm: A case-control study
}

\author{
Eunju Kim, Seung-Won Yi, Sang-lk Oh, Kyoung-Min So, Younghun Jung, Han Gyu Lee, Joon Ki Hong, Eun Seok Cho, \\ Young-Sin Kim, Tai-Young Hur*
}

National Institute of Animal Science, Rural Development Administration, Wanju 55365, Korea

Received October 15, 2021

Accepted December 8, 2021

Corresponding author:

Tai-Young Hur

E-mail: tyohur@korea.kr

https://orcid.org/0000-0003-3129-2942
Severe outbreaks of porcine epidemic diarrhoea virus (PEDV) have continued to re-emerge worldwide. Because of the high mortality rate of suckling piglets in PEDV outbreaks, the disease causes significant economic losses in the pig industry. The limited pre-existing immunity against this virus is thought to cause an explosive increase in infection in pig farms. This study aimed to evaluate the clinical symptoms of PEDV after intentional exposure (feedback). During the first few days of the outbreak in a breeding pig farm, 14 sows showed watery diarrhoea, and the disease subsequently spread rapidly throughout the barn. Pigs that were intentionally exposed to PEDV $(n=251)$ showed watery diarrhoea $(46.6 \%)$, reduced appetite (17.5\%), and vomiting (6.0\%). However, 75 exposed pigs (29.9\%) showed no clinical signs of disease. Four weeks after the feedback challenge, 34 sows gave birth to litters of piglets, which survived with no diarrhoea. Five weeks after the start of the outbreak, PEDV was not detected in any of the examined samples, including environmental swabs. Thus, early diagnosis, prompt establishment of herd immunity, and strict application of biosecurity are good practices to reduce the mortality rates among new-born piglets and control economic losses in pig farms showing PEDV outbreaks.

Key Words: Porcine epidemic diarrhoea, Feedback challenge, Intentional exposure, Herd immunity

\section{INTRODUCTION}

The porcine epidemic diarrhoea virus (PEDV) is a highly contagious, enveloped, single-stranded positive RNA virus of the genus Alphacoronavirus in the family Coronaviridae (Jung and Saif, 2015; Lee, 2015; Lee et al, 2019; Jung et al, 2020). Since its first reported appearance in the United Kingdom in 1971 (Wood, 1977), this virus spread to other European countries through the 1970s and the 1980s (Pijpers et al, 1993; Tobler et al, 1994), Asian countries in the 1990s (Kweon et al, 1993; Chen et al, 2010), and the United States (Stevenson et al, 2013; Schulz and Tonsor, 2015) in 2013. While PED outbreaks occur periodically in these countries, the outbreaks in the United States occurred and rapidly spread across the country as well as neighbouring countries such as Canada and Mexico. The disease has caused the death of more than 8 million new-born piglets, resulting in losses of 97 billion USD in the pork industry, with the losses over a year-long epidemic in the United States amounting to millions of dollars (Schulz and Tonsor, 2015). The first PEDV epizootic in the Republic of Korea occurred in 1992. Specifically, a PEDV outbreak occurred in the national herd and killed approximately 25,000 piglets in 146 cases during 2013 2014, and an outbreak was reported in the subsequent year (Kim et al, 2015). Outbreaks on seronegative farms are clinically characterised by the sudden occurrence of severe watery diarrhoea and/or vomiting and significantly reduced appetite, which affects pigs of all ages, although the severity of PED differs according to the age of the pigs (Stevenson et al, 2013; Jung and Saif, 2015). While 
adult pigs typically recover, PEDV can kill $80 \% \sim 100 \%$ of piglets, causing substantial economic losses (Jung et al, 2020). Faecal-to-oral transmission is the major route for direct transmission of PEDV (Jung and Saif, 2015). Indirect transmission also occurs frequently within and between farms via other contaminated fomites, including transport trailers, farm workers' hands, boots, and clothes, and feed totes used for transporting bulk feed or feed ingredients (Jung and Saif, 2015; Kim et al, 2015). PEDV infection can be costly and difficult to control and often prevents efficient production in the intensive swine industry. Immunisation of pregnant sows is important for controlling and reducing the mortality of suckling piglets against PED (Jung and Saif, 2015; Langel et al, 2020). Although no specific treatment is available for PED, live and inactivated PED vaccines have been used for 10 years to provide protection against PED in Korea as well as other sites of PED outbreaks (Gao et al, 2013). Many commercial vaccines are considered effective and have been widely used, but not all animals develop sufficient lactogenic immunity (Song et al, 2015). The most common practice used to initiate herd immunity in pig farms in the US during the 2013 2017 epidemic, when no PEDV vaccines were available, was the use of whole-herd feedback by using a load-close-exposure protocol and feedback-stimulated lactogenic immunity via the gut-mammary-sIgA axis in sows, which afforded prolonged, passive immune protection of piglets against PEDV infection (Jung and Saif, 2015). However, a standard feedback protocol with consistently high efficacy has not been proposed for any type of pig-production system. Thus, we aimed to measure the clinical response to intentional exposure to PEDV in breeding sows.

\section{SUBJECTS AND METHODS}

The farm was a 200-sow breed-to-wean facility closed to the introduction of live gilts, with a policy of vaccination against PED/TGE in pregnant sows and a shower-in-shower-out site with excellent management and biosecurity. Workers who specialised in pig farms visited the farm for repairing feeding equipment in a breeding room a week before the outbreak. The clinical signs of the outbreak began with watery foetid diarrhoea in three pregnant sows in a breeding room on 23 March 2020. The antibiotic treatment initiated was ineffective. The next day, 14 sows in the same barn showed similar diarrhoea, and 18\% (27/251) of the pigs, including boars, showed diarrhoea within a week. In diagnostic investigations, faecal samples from rectal swabs were randomly collected from 20 pigs with watery diarrhoea, and 11 samples showed positive results for PEDV in an RT-PCR test. Nucleotide analyses of the virus showed the highest similarity (99.4\%) to the PEDV strains reported in 2013 from the US (Fig. 1). Strict application of biosecurity protocols was recommended, including movement restriction of animals, separated workers, and minimal sharing of tools on the farm. Cleaning and disinfection were conducted daily until the virus was undetectable. We developed a plan to manage and control all breeding herds (including hogs) and immunise pregnant sows to protect new-born piglets with immunity against PEDV infection. The diarrhoea faeces were collected from virus-infected sows known to be PEDV-positive by RT-PCR, mixed with food and water, and fed to all breeding herds on the farm. The feedback of pooled diarrhoeic faeces from affected animals was continued for all adult pigs until they showed clinical signs. Pigs with no symptoms continued to receive the feedback for 2 weeks. After a week, 10 rectal swab samples, including five samples each from pigs with and without diarrhoea, showed PEDV on 4 April.

\section{Statistics}

Statistical analyses were performed using SPSS software version 21 (IBM, Armonk, NY, USA). For all analyses, $P$ values were derived from Pearson's chi-squared test for clinical signs according to age groups (vaccinated/non-vaccinated) and individual breeds. Statistical significance was set at $P<0.05$. 


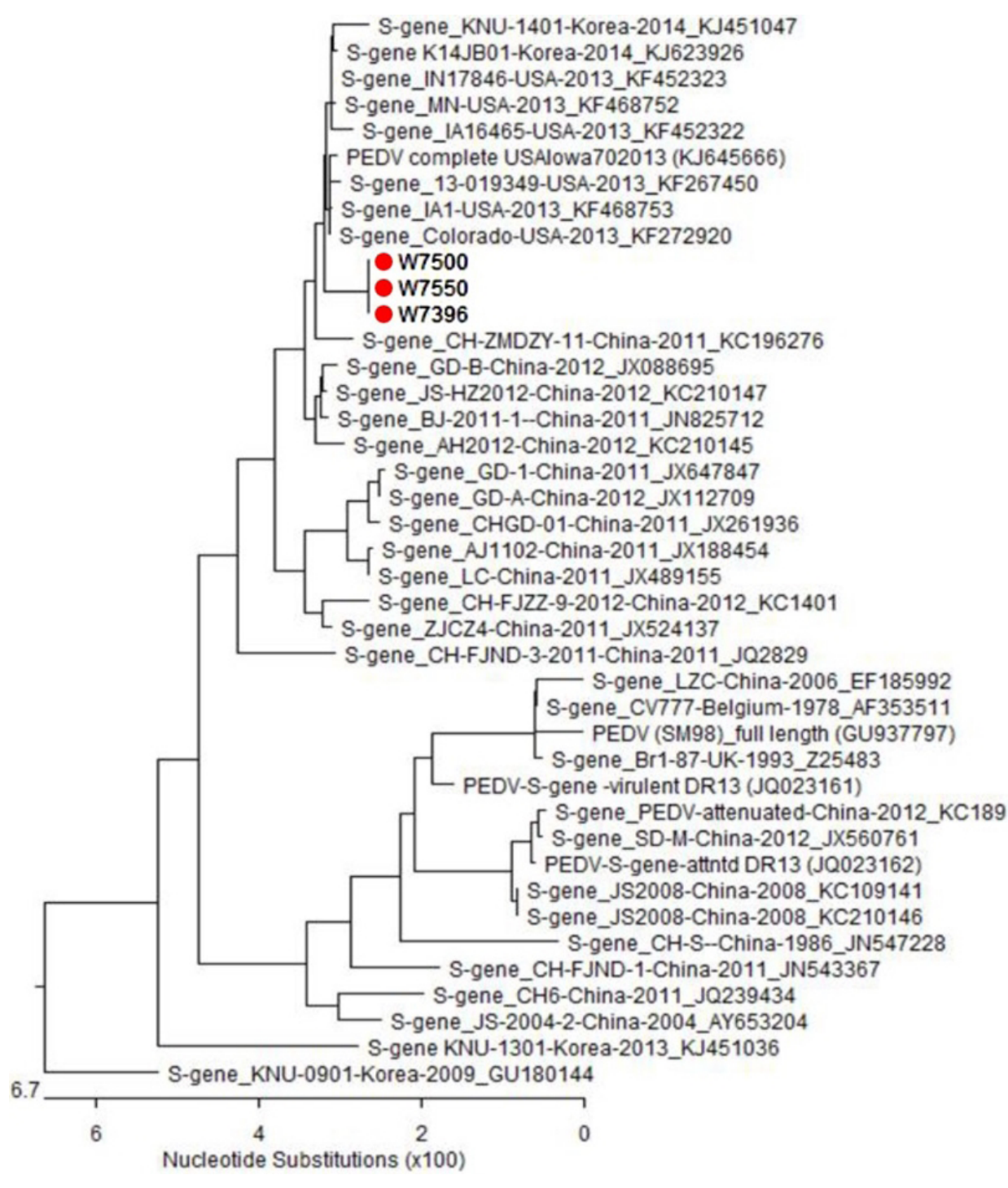

Fig. 1. Phylogenetic analysis of the three PEDV strains (W7500, W7550, W7396) used in this study that showed $99.4 \%$ similarity to the PEDV strain USA/Colorado/2013 (KF272920). PEDV, Porcine epidemic diarrhoea virus.

\section{RESULTS}

Only one pig with diarrhoea still released the virus, and no virus was detected in pigs that were asymptomatic. Virus infection did not seriously affect the adult pigs, who showed return of appetite and cessation of the diarrhoea within 3 14 days after the feedback. During the virus exposure period, some weaned piglets (age $>5$ weeks) showed diarrhoea in the weaning rooms. Pooled faecal samples were collected from eight weaning rooms, and the samples from two rooms showed PEDV. Antibiotic treatment was initiated in all piglets to prevent secondary bacterial infections. Additionally, rigid disinfection was performed once daily to reduce or eliminate the virus from the environment. All affected piglets recovered soon, and no deaths occurred during this period. Four weeks after the feedback challenge, 34 sows gave birth to litters of piglets. The sows and suckling piglets showed no remarkable clinical signs, and none of the new-born piglets died of diarrhoea. Protective immunity (100\% survival rate of the piglets challenged with field virulent virus) was induced in all breeding groups inoculated orally during the PEDV outbreak. Serum samples from sows that gave birth were collected and evaluated for neutralising antibodies. The neutralising antibody titres in the serum samples were 
$<8$ to 64 in all infected sows. Among the 224 pigs that received feedback, $46.6 \%$ showed at least one of the symptoms, including diarrhoea, vomiting, or loss of appetite, within 5 days, while $66.52 \%$ showed symptoms within 10 days (Fig. 2). The number of pigs with clinical responses is shown in Table 1. Diarrhoea, vomiting, and loss of appetite were observed in $46.6 \%(n=117), 6.0 \%$ $(n=15)$, and $17.5 \%(n=44)$ of the pigs, while $29.9 \%(n=75)$ showed no clinical signs. All boars that had never been vaccinated showed clinical signs, while only $62.1 \%$ of the sows that were vaccinated showed signs. Additionally, significant differences were observed in the clinical response to feedback among the breeds in this study $(P<0.000)$ (Table 2).

\section{DISCUSSION}

In this study, we evaluated the appearance of clinical signs during the feedback protocol for PEDV eradication in a breeding pig farm. The clinical symptoms in vaccinated female and unvaccinated male pigs differed significantly. Although both modified live and killed vaccines against PEDV are commercially available in Korea, the continuing PED epidemics indicate the low effectiveness of domestic vaccines (Lee et al, 2019). PED caused by PEDV is also becoming increasingly serious in China, and current vaccines have been shown to be ineffective on most swine farms ( $\mathrm{Li}$ et al, 2014). In the US, the variable efficacies of PEDV vaccines capable of eliciting lactogenic protective immunity may lead multiple production systems to adapt feedback exposure protocols to protect against disease (Chasey and Cartwright, 1978; Jung and Saif, 2015). In the farm in this study, although sows were vaccinated before childbirth, field virus infections occurred; symptoms such as diarrhoea appeared even after feedback, and the virus was excreted in faeces. Faecal virus excretion in sows is a very important factor influencing the viral infection of piglets as PEDV-mediated diarrhoea and the high piglet mortality rates cause substantial losses in the swine

Table 1. Comparison of clinical responses after intentional exposure to PEDV-contaminated faeces between vaccinated sows and non-vaccinated boars

\begin{tabular}{lccc}
\hline \multicolumn{1}{c}{ Category } & $\begin{array}{c}\text { Sows* } \\
\text { (Vaccinated) }\end{array}$ & $\begin{array}{c}\text { Boars* (Non- } \\
\text { vaccinated) }\end{array}$ & Total \\
\hline Pigs with clinical signs & & & \\
$\quad$ Diarrhoea (\%) & $65(25.9)$ & $52(20.7)$ & $117(46.6)$ \\
$\quad$ Vomiting (\%) & $15(6.0)$ & $0(0)$ & $15(6.0)$ \\
$\quad$ Anorexia (\%) & $43(21.7)$ & $1(1.9)$ & $44(17.5)$ \\
Subtotal & $123(49.0)$ & $53(21.1)$ & $176(70.1)$ \\
Pigs without clinical signs & & & \\
$\quad$ No clinical sign (\%) & $75(37.9)$ & $0(0)$ & $75(29.9)$ \\
Total & $198(78.9)$ & $53(21.1)$ & $251(100)$
\end{tabular}

$* P<0.000$.

PEDV, porcine epidemic diarrhoea virus.

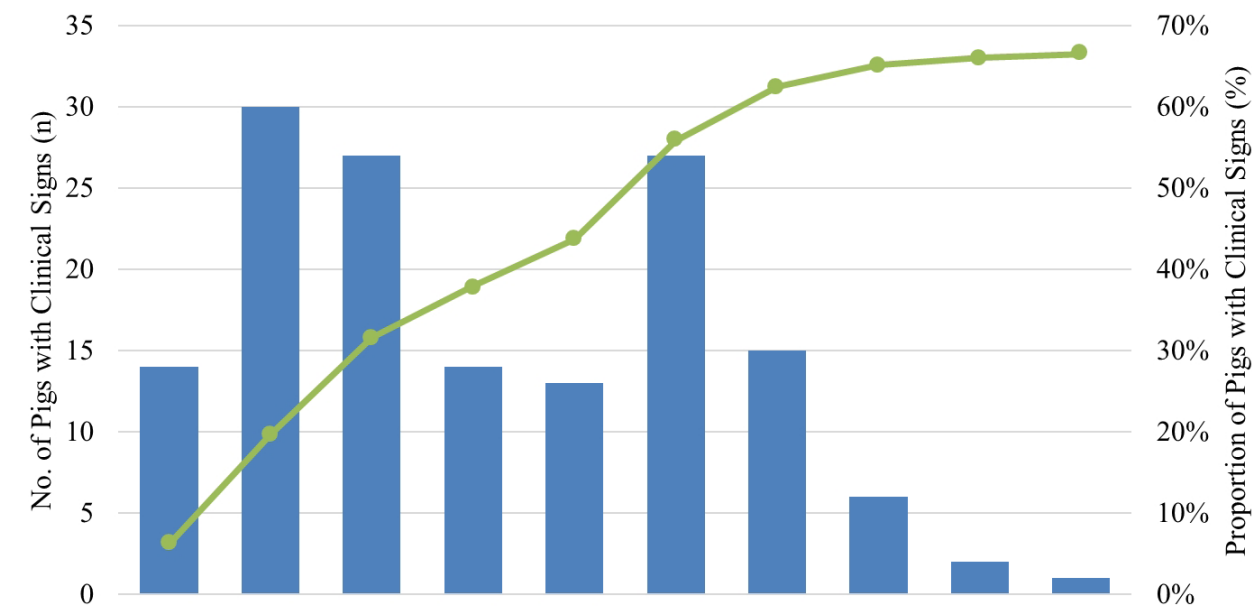

Day 1 Day 2 Day 3 Day 4 Day 5 Day 6 Day 7 Day 8 Day 9 Day 10 
Table 2. Number of adult pigs with and without clinical response after intentional exposure to PEDV-contaminated faeces according to pig breeds

\begin{tabular}{|c|c|c|c|c|c|c|}
\hline Breeds** & $A^{*}$ & $\mathrm{~B}^{* *}$ & $\mathrm{C}$ & $\mathrm{D}$ & $\mathrm{E}$ & Total \\
\hline \multicolumn{7}{|l|}{ Pig with clinical signs } \\
\hline Vomiting (\%) & $1(2.1)$ & $0(0)$ & $14(25.9)$ & $0(0)$ & $0(0)$ & $15(6.0)$ \\
\hline Diarrhoea $(\%)$ & $15(31.9)$ & $6(50.0)$ & $29(53.7)$ & $10(31.3)$ & $57(53.8)$ & $117(46.6)$ \\
\hline Anorexia (\%) & $9(19.1)$ & $1(8.3)$ & $11(20.4)$ & $11(34.4)$ & $12(11.3)$ & $44(17.5)$ \\
\hline Subtotal & $25(53.2)$ & $7(58.3)$ & $54(100)$ & $21(65.6)$ & $69(65.1)$ & $176(70.1)$ \\
\hline \multicolumn{7}{|c|}{ Pigs without clinical signs } \\
\hline No clinical sign (\%) & $22(46.8)$ & $5(41.7)$ & $0(0)$ & $11(34.4)$ & $37(34.9)$ & 75 (29.9) \\
\hline Total & $47(100)$ & $12(100)$ & $54(100)$ & $32(100)$ & $106(100)$ & $251(100)$ \\
\hline
\end{tabular}

$* P<0.005$. $* * P<0.000$.

PEDV, porcine epidemic diarrhoea virus.

industry. Therefore, we mainly focused on reducing the mortality of new-born piglets. Experimental infection using feedback of PEDV-infected material by oral dosing has been described previously (Stevenson et al, 2013; Jung and Saif, 2015; Clement et al, 2016; Langel et al, 2016; Egelkrout et al, 2020). Similarly, during PEDV outbreaks in farms, pregnant sows have been intentionally exposed to virus-contaminated materials such as faeces and/or the intestinal tissue of affected animals to stimulate lactogenic immunity and reduce the duration of outbreaks (Pensaert and Yeo, 2006). This method involves closing the herd to introductions and then exposing all present animals through feedback to facilitate simultaneous infection of all sows. However, this method can cause complications such as prolonged postexposure PEDV shedding during lactation leading to infection in piglets (Goede and Morrison, 2016). Moreover, gilts exposed to the virus earlier (day 19 22) or later (day 96 97) in the gestation period may show less protective immunity, as evidenced by $87.2 \%$ and $55.9 \%$ survival rates of their piglets, respectively (Langel et al, 2016). Sows given feedback or orally inoculated with virulent PEDV during mid-gestation may also discontinue faecal PEDV shedding prior to farrowing (Langel et al, 2019). In our study, virus shedding was undetectable 4 weeks after starting feedback in pregnant sows, and no new-born piglets died. Although the protective mechanism underlying feedback-induced immunity is not fully established, it may be attributable to virus replication in the mucosal epithelium and the transfer of mucosal effectors of protective immunity from the exposed sow to the piglet through milk or colostrum. The PEDV-specific IgA antibody levels in the colostrum/ milk of dams can indicate the extent of passive immunity of their piglets (Langel et al, 2016), and differences in the frequency and duration of feedback protocols could influence the titre of neutralising antibodies against PEDV. In one study, 100\% of sows that received feedback three times a week showed positive results for PEDV neutralising antibodies in serum samples by the fluorescent focus neutralisation (FFN) test at 6th week, while $95 \%$ of sows that received feedback once a week showed sero-positivity at the same time point (Clement et al, 2016). In our study, virus neutralisation antibodies against PEDV increased 8- to 64-fold in the sow serum samples. Thus, the lactogenic immunity status of sows was improved by feedback, even though we could not determine the neutralising antibody level in colostrum from sows. Several factors can influence PED outbreaks on farms, including low immunity levels of sows, and introduction of PEDV due to inadequate biosecurity. Efforts to eradicate PEDV from farm environments should include closing the herd to introductions and exposing all animals through the feedback program to infect all sows simultaneously. This can stimulate sufficient herd immunity, which, in conjunction with aggressive environmental cleaning and restricted movement of sows and pigs, can eliminate the virus from the premises. 
After the clinical signs subside, it could be more important for PEDV-uninfected pigs once a herd is found infected. PEDV can survive in dry feed for 7 days and in wet feed for 28 days when stored at room temperature (Goyal S., 2014). Thus, environmental control plays a key role in stopping the continuous circulation and transmission of PEDV in farms. In this study, we segregated the pig-breeding area, divided the workers, and recommended against sharing of tools. Daily disinfection was performed to minimise the remaining virus in the environment; thus, no virus was detected in the environment and sow faeces when the sows gave birth, and none of the piglets died due to diarrhoea. A coordinated approach is essential to prevent PEDV introduction, promote early detection of PEDV, control disease, and minimise the spread of infection. Early diagnosis, establishment of herd immunity, and strict application of biosecurity standards are good practices to diminish the mortality of new-born piglets and economic losses in pig farms.

\section{ACKNOWLEDGEMENTS}

This work was carried out with the support of "Cooperative Research Program for Agriculture Science \& Technology Development (Project title: The improvement of animal diseases control in National Institute of Animal Science, PJ01567602)” Rural Development Administration, Republic of Korea.

\section{CONFLICT OF INTEREST}

No potential conflict of interest relevant to this article was reported.

\section{ORCID}

Eunju Kim, https://orcid.org/0000-0003-4040-0474 Seung-Won Yi, https://orcid.org/0000-0001-5545-2969 Sang-Ik Oh, https://orcid.org/0000-0003-0877-9170 Kyoung-Min So, https://orcid.org/0000-0001-9497-3345
Younghun Jung, https://orcid.org/0000-0002-8094-0304

Han Gyu Lee, https://orcid.org/0000-0002-3531-1971

Joon Ki Hong, https://orcid.org/0000-0001-8272-1263

Eun Seok Cho, https://orcid.org/0000-0001-5223-099X

Young-Sin Kim, https://orcid.org/0000-0001-5466-8813

Tai-Young Hur, https://orcid.org/0000-0003-3129-2942

\section{REFERENCES}

Chasey D, Cartwright SF. 1978. Virus-like particles associated with porcine epidemic diarrhoea. Res Vet Sci 25: 255-256.

Chen J, Wang C, Shi H, Qiu H, Liu S, Chen X, Zhang Z, Feng L. 2010. Molecular epidemiology of porcine epidemic diarrhea virus in China. Arch Virol 155: 1471-1476.

Clement T, Singrey A, Lawson S, Okda F, Nelson J, Diel D, Nelson EA, Christopher-Hennings J. 2016. Measurement of neutralizing antibodies against porcine epidemic diarrhea virus in sow serum, colostrum, and milk samples and in piglet serum samples after feedback. J Swine Health Prod 24: 147-153.

Egelkrout E, Hayden C, Fake G, Keener T, Arruda P, Saltzman R, Walker J, Howard J. 2020. Oral delivery of maize-produced porcine epidemic diarrhea virus spike protein elicits neutralizing antibodies in pigs. Plant Cell Tissue Organ Culture: 1-8.

Gao Y, Kou Q, Ge X, Zhou L, Guo X, Yang H. 2013. Phylogenetic analysis of porcine epidemic diarrhea virus field strains prevailing recently in China. Arch Virol 158: 711-715.

Goede D, Morrison RB. 2016. Production impact \& time to stability in sow herds infected with porcine epidemic diarrhea virus (PEDV). Prev Vet Med 123: 202-207.

Goyal S. 2014. Interventions to control PEDV in feed and feed ingredients. Dostupno na http://www. pork. org/pedv-2014-research/pedv-feed.

Jung K, Saif LJ, Wang Q. 2020. Porcine epidemic diarrhea virus (PEDV): An update on etiology, transmission, pathogenesis, and prevention and control. 
Virus Res 286: 198045.

Jung K, Saif LJ. 2015. Porcine epidemic diarrhea virus infection: Etiology, epidemiology, pathogenesis and immunoprophylaxis. Vet J 204 :134-143.

Kim SH, Lee JM, Jung J, Kim IJ, Hyun BH, Kim HI, Park CK, Oem JK, Kim YH, Lee MH, Lee KK. 2015. Genetic characterization of porcine epidemic diarrhea virus in Korea from 1998 to 2013. Arch Virol 160: 1055-1064.

Kweon CH, Kwon BJ, Jung TS, Kee YJ, Hur DH, Hwang EK, Rhee JC, An SH. 1993. Isolation of porcine epidemic diarrhea virus (PEDV) in Korea. Korea J Vet Res 33: 249-254.

Langel SN, Paim FC, Lager KM, Vlasova AN, Saif LJ. 2016. Lactogenic immunity and vaccines for porcine epidemic diarrhea virus (PEDV): Historical and current concepts. Virus Res 226: 93-107.

Lee C. 2015. Porcine epidemic diarrhea virus: An emerging and re-emerging epizootic swine virus. Virol J 12: 193.

Lee S, Lee DU, Noh YH, Lee SC, Choi HW, Yang HS, Seol JH, Mun SH, Kang WM, Yoo H, Lee C. 2019. Molecular characteristics and pathogenic assessment of porcine epidemic diarrhoea virus isolates from the 2018 endemic outbreaks on Jeju Island, South Korea. Transbound Emerg Dis 66: 18941909.

Li R, Qiao S, Yang Y, Su Y, Zhao P, Zhou E, Zhang G. 2014. Phylogenetic analysis of porcine epidemic diarrhea virus (PEDV) field strains in central China based on the ORF3 gene and the main neutralization epitopes. Arch Virol 159: 1057-1065.

Pensaert MB, Yeo SG. 2006. Porcine epidemic diarrhea. pp. 367-372. In: Straw BE, Zimmerman JJ, D’Allaire S, Taylor DJ(ed). Diseases of Swine. Ames, Blackwell.

Pijpers A, van Nieuwstadt AP, Terpstra C, Verheijden JH. 1993. Porcine epidemic diarrhoea virus as a cause of persistent diarrhoea in a herd of breeding and finishing pigs. Vet Rec 132: 129-131.

Schulz LL, Tonsor GT. 2015. Assessment of the economic impacts of porcine epidemic diarrhea virus in the United States. J Anim Sci 93: 5111-5118.

Song D, Moon H, Kang B. 2015. Porcine epidemic diarrhea: a review of current epidemiology and available vaccines. Clin Exp Vaccine Res 4: 166-176.

Stevenson GW, Hoang H, Schwartz KJ, Burrough ER, Sun D, Madson D, et al. 2013. Emergence of porcine epidemic diarrhea virus in the United States: clinical signs, lesions, and viral genomic sequences. J Vet Diagn Invest 25: 649-654.

Tobler K, Bridgen A, Ackermann M. 1994. Sequence analysis of the nucleocapsid protein gene of porcine epidemic diarrhoea virus. In: Coronaviruses. pp. 49-54.

Wood EN. 1977. An apparently new syndrome of porcine epidemic diarrhoea. Vet Rec 100: 243-244. 